\title{
ILCEA
}

Revue de l'Institut des langues et cultures

d'Europe, Amérique, Afrique, Asie et Australie

16 | 2012

La culture progressiste à l'époque de la guerre froide

\section{La culture " progressiste » pendant la guerre froide (1945-1989)}

\section{François Genton et Edmond Raillard}

\section{OpenEdition}

Journals

Édition électronique

URL : http://journals.openedition.org/ilcea/1596

DOI : 10.4000/ilcea.1596

ISSN : 2101-0609

\section{Éditeur}

UGA Éditions/Université Grenoble Alpes

\section{Édition imprimée}

ISBN : 978-2-84310-232-5

ISSN : 1639-6073

Référence électronique

François Genton et Edmond Raillard, « La culture «progressiste » pendant la guerre froide

(1945-1989) », ILCEA [En ligne], 16 | 2012, mis en ligne le 04 juillet 2012, consulté le 22 mars 2021.

URL : http://journals.openedition.org/ilcea/1596 ; DOI : https://doi.org/10.4000/ilcea.1596

Ce document a été généré automatiquement le 22 mars 2021.

(C) ILCEA 


\title{
La culture « progressiste » pendant la guerre froide (1945-1989)
}

\author{
François Genton et Edmond Raillard
}

1 La guerre froide fut aussi un phénomène culturel: tandis que le mouvement communiste prétendait relancer le combat antifasciste des années 1930 en mobilisant les milieux culturels contre l'« impérialisme yankee », les puissances du « monde libre » enrôlaient de nombreux intellectuels et artistes pour dénoncer le "péril rouge », la répression et les crimes staliniens. Le contrôle exercé sur l'art et la pensée par les gouvernements et leurs services fut déclaré et brutal à l'Est, et, quoique plus subtil, bien réel à l'Ouest. Une position intermédiaire ou nuancée était immanquablement perçue comme une marque d'allégeance au camp adverse.

2 La guerre idéologique n'a cependant pas dispensé les artistes et les intellectuels de chaque camp de traiter les mêmes questions : quelles leçons tirer des horreurs de la période précédente pour l'interprétation du passé, la construction de l'avenir et l'action présente? Sur quels principes fallait-il fonder désormais l'action politique, économique et sociale? Comment les intellectuels et les artistes devaient-ils concevoir leur «engagement» en faveur d'une cause politique et leur rapport au pouvoir politique ? L'art se devait-il de répondre à une intention, ou au contraire était-il vain de vouloir le réduire à des objectifs sociaux et politiques? À ces questions, qui d'une certaine manière réactualisaient celles des années 1920 et 1930, s'en ajoutaient de nouvelles: la conscience du péril nucléaire, la reconstruction des territoires ravagés par la guerre, la décolonisation et l'irruption du Tiers Monde et des pays non alignés sur la scène culturelle et politique, la naissance de la société de consommation, le début de la conquête de l'espace, l'ouverture des enseignements secondaire et supérieur à des milieux qui en étaient traditionnellement exclus, le développement exponentiel de la culture populaire moderne et des moyens techniques de diffusion et de reproduction (disque vinyle, télévision, transistor, magnétophone) et la position dominante des États-Unis dans de nombreux secteurs, de la bande dessinée à l'art contemporain, du cinéma et de la télévision à la musique populaire. Grâce à l'expansion et au 
rayonnement de la culture populaire anglo-saxonne, le «monde libre » bénéficiait d'un atout majeur auprès de la jeunesse des pays industrialisés.

De nos jours, la plupart des spécialistes de la vie culturelle durant la guerre froide mettent à juste titre l'accent sur l'américanisation de la culture populaire et sur l'évolution de l'organisation et du contrôle politiques dans les États et entre les États, constatant l'échec du socialisme réel, tout en reconnaissant des spécificités nationales au sein même du bloc soviétique, par exemple une rupture entre "société réelle et société proclamée » plus importante en Europe de l'Est qu'en Russie ${ }^{1}$. Ce livre pose autrement la question du bilan. Tentant de dépasser une vision seulement politique de l'antagonisme entre les blocs et en s'appuyant avec toute la prudence requise sur la notion de " culture progressiste » ou " culture du camp progressiste », il s'intéresse aux productions artistiques et intellectuelles qui à l'Est comme à l'Ouest ont tenté de penser et de transformer le monde d'après 1945. Par "culture progressiste », il faut entendre toute production culturelle, c'est-à-dire artistique et intellectuelle, qui pense contribuer au progrès, qu'il s'agisse d'une avant-garde artistique (par exemple dans les arts visuels et la musique contemporaine), d'une forme d'expression en expansion à défaut d'être tout à fait neuve (musique pop, bande dessinée) ou d'une réflexion plus théorique sur le travail, la technique, l'homme en tant qu'individu et être social. À la croisée des Cultural Studies et de l'histoire intellectuelle et politique, ce recueil prend la suite de réflexions conduites au sein de l'Institut des langues et des cultures d'Europe et d'Amérique (ILCEA) de l'université de Grenoble par exemple sur les diverses implications, notamment au $\mathrm{xx}^{\mathrm{e}}$ siècle, de la notion de "petite patrie » (Heimat) ou sur les transitions démocratiques en Europe et en Amérique au cours du $\mathrm{xx}^{\mathrm{e}}$ siècle $^{2}$.

Ce livre, qui rassemble les études élaborées à partir d'exposés tenus les 15 et 16 septembre 2011 à l'université de Grenoble ${ }^{3}$, s'ouvre sur deux textes des cinéastes berlinois Barbara et Winfried Junge. En 1961, année de la construction du Mur de Berlin, le réalisateur a commencé à filmer les élèves d'un cours préparatoire de l'école de Golzow, un village situé à $80 \mathrm{~km}$ à l'est de Berlin. Le projet a été poursuivi jusqu'en 2007. À partir de 1992 Barbara Junge, qui montait les films liés au projet depuis 1983, les a coréalisés. Le 15 septembre 2011, un public nombreux a vu à Mon Ciné à Saint-Martind'Hères un extrait du film Lignes de vie (Lebensläufe 1980-19814). Il pouvait comprendre ainsi comment se jouait le passage de l'enfance à l'adolescence et à l'âge adulte en Allemagne de l'Est: école primaire, formation professionnelle, études, armée, entreprises, mariage, enfants... Ce film, qui est une grande réussite artistique, représente un témoignage unique et passionnant ainsi qu'une chronique indispensable à qui veut se faire une idée de la vie dans les "démocraties populaires » jusqu'au début de la décennie qui se termina par la chute du Mur. L'observation a été poursuivie jusqu'en 2007, offrant un tableau saisissant des bouleversements qui suivirent la fin de la guerre froide dans cette région plutôt déshéritée de l'ex-RDA. Plus que de nombreux projets similaires entrepris ultérieurement et qui sont étroitement dépendants d'un format adapté aux impératifs de la télévision ${ }^{5}$, les films du projet Les Enfants de Golzow vont au fond des choses et des êtres, sans imposer un point de vue, même si, comme on le verra dans les textes de ce livre, les auteurs ne cachent pas ce qu'ils doivent à la RDA, un État qui leur a offert une possibilité de s'épanouir sur le plan professionnel et intellectuel. On peut d'ailleurs penser, comme l'exprimèrent plusieurs personnes dans le public qui découvrait ces films, que dans les années 1970 la vie dans la campagne brandebourgeoise n'était pas radicalement différente de celle que l'on menait dans les 
campagnes françaises. Les implications spécifiques du système politique de la RDA étant par ailleurs bien visibles dans le film, le fait que la réalité vécue de la RDA ne se limitait pas aux aspects répressifs du régime en était d'autant plus évident : ici aussi se posaient les problèmes de la vie quotidienne dans les pays industrialisés de la fin du $\mathrm{xx}^{\mathrm{e}}$ siècle, une revendication d'émancipation, d'autonomie et de confort chez les jeunes, l'importance du premier travail, du premier appartement, et, en amont, celle de la formation professionnelle, du service militaire pour les garçons, de la première maternité pour les jeunes femmes. D'une certaine manière, ce film donnait le ton : l'Est aussi devait affronter les défis du monde moderne et trouver des réponses adéquates, qu'il fallait toutefois adapter aux impératifs politiques et idéologiques des gouvernements, une contradiction dont nous savons que ces derniers ne sont pas parvenus à la surmonter. Cet échec n'autorise nullement à considérer que la vie dans les sociétés des " démocraties populaires » ne présente aucun intérêt. Il en va de même pour la vie dans les sociétés soumises à des dictatures d'extrême droite, par exemple la société espagnole à l'époque du franquisme: ici aussi, on retrouve les mêmes revendications que dans les autres pays du monde développé "capitaliste» et "socialiste ", d'un côté la volonté de rejoindre les avant-gardes artistiques de pays qui ne connaissent pas une censure envahissante, de l'autre celle de suivre le mouvement général vers la création d'une culture « pop » ouverte.

Les contributions suivantes sont réparties en six chapitres: "Créativité et culture: deux blocs que tout oppose ? ", « Arts visuels (peinture et bande dessinée) », « Arts du spectacle (cinéma, théâtre et danse)», «Musique (chanson et musique contemporaine) », «Le roman » et « Médiations ».

Le premier texte du chapitre «Créativité et culture » donne d'une certaine manière le ton de l'ouvrage : d'un côté la recherche sur la créativité, vitale pour des économies qui visent un développement technique et scientifique rapide, inspire à l'Est comme à l'Ouest des approches théoriques recelant de fortes analogies (C. Mareis) tandis que de l'autre la tentative de faire des forces armées un acteur culturel majeur est une spécificité socialiste, ici en Tchécoslovaquie, plutôt un échec à l'époque du stalinisme, mais durant la décennie de la déstalinisation un processus prometteur auquel met fin en 1968 l'occupation du pays par les troupes du Pacte de Varsovie (V. Šmidrkal).

7 On retrouve la même volonté d'abolir les séparations entre l'art et la vie dans les « révolutions culturelles » d'Union soviétique à la fin des années 1920 et de RDA à la fin des années 1950: ce premier texte du chapitre "arts visuels» évoque une normalisation qui mit fin à des expériences susceptibles de se retourner contre le pouvoir en place (E. Gillen). L'abstraction fut aussi un concept idéologique à double usage: tandis que la RFA célébrait la peinture abstraite pour mieux dénoncer la doctrine autoritaire du réalisme socialiste, la RDA s'en prenait au "formalisme " décadent de l'Occident. Une polémique en partie étrangère à la peinture réellement pratiquée dans les deux États, où l'abstraction et la figuration coexistent (P. Neau). Dans l'Espagne des années de transition démocratique on repense l'histoire de l'art en tant qu'histoire d'une autonomisation et l'on réévalue l'apport d'écoles antifranquistes telles que l'informalisme, le réalisme social et la géométrie abstraite, une révision de la pensée dominante de l'art qui se répercute dans les expositions et les musées ( $\mathrm{N}$. de Haro Garcia). Le franquisme avait cependant su s'adapter et bousculer le conservatisme traditionnel des institutions et des milieux qui le soutenaient en organisant des expositions officielles d'art abstrait dans les années 1950. Il prétendait ainsi se donner 
l'image d'un pays digne du "monde libre " et de l'alliance avec les États-Unis (K. Raminger). À la fin des années 1970 naît le conceptualisme moscovite, un nom qui évoque celui d'une école occidentale de la décennie précédente. À la différence des artistes occidentaux, les postmodernistes russes, marqués par leur volonté de se démarquer de l'emprise et du mensonge des discours officiels, continuent de croire à l'art en tant que forme supérieure d'existence (I. Desprès). La bande dessinée de la Pologne socialiste, considérée au départ comme un art occidental "dégénéré », fut bientôt utilisée au bénéfice de la propagande officielle et connut une popularité et un essor grandissants, tandis qu'au fil des décennies, surtout à la fin des années 1980, la censure reculait de plus en plus, permettant à cet art d'exercer une fonction critique, annonciatrice de la fin du régime (J. Rzeszotnik).

8 Le chapitre "Arts du spectacle» commence par l'étude de la critique du thriller politique $Z$ du réalisateur Costa Gavras (et du scénariste Jorge Semprun) dans les milieux intellectuels «gauchistes » de la France de la fin des années 1960. Ces derniers condamnèrent une esthétique « commerciale » quand le Parti communiste français, qui approuvait dans un premier temps l'engagement antifasciste de ce film, était conduit à réviser sa position à propos de L'Aveu, film inspiré aux auteurs de $Z$ par les mémoires d'Artur London, victime du Procès de Prague (1952). Cette forme de cinéma "engagé " - et les discussions qu'elle suscita- ne résistèrent guère à la fin de l'illusion communiste (M. Ruiz Galbete). La trilogie théâtrale d'Edward Bond Pièces de guerre (1983-1985) passa relativement inaperçue en Grande Bretagne et suscita un grand intérêt dans la France des années 1990 : il s'agissait moins d'affronter le péril nucléaire, qui n'occupait plus le devant de l'actualité, que de penser les guerres génocidaires ou les massacres de masse récents (D. Tuaillon). La danse "classique » et contemporaine est l'enjeu d'une concurrence des systèmes politiques dans les années 1950 et 1960 : les tournées des grandes compagnies soviétiques sont une "arme diplomatique " au service de la politique étrangère de l'URSS, mais la danse est aussi un art où s'exprime l'attractivité du monde libre qui attire les transfuges, en partie parce qu'une chorégraphie d'avant-garde peut s'y exprimer et se développer (S. Gonçalves).

M. Alten, dans le chapitre consacré à la musique, s'intéresse à la firme discographique Le Chant du Monde qui, dans la mouvance du mouvement communiste international et du Parti Communiste français, transmit une culture musicale variée et dans l'ensemble plutôt exigeante à un public qui en grande partie n'y avait pas accès auparavant. Les goûts dominants et la chute du communisme auront eu raison d'une entreprise dont on peut penser qu'elle n'a pas véritablement été remplacée. Le répertoire folk de Pete Seeger, édité en France au Chant du Monde, a inspiré la création musicale en RDA, notamment une tentative de créer une musique à la fois moderne et officielle. La scène musicale est-allemande a connu des tensions, des contradictions et une grande variété d'inspirations et de tendances, de la propagande quasi-officielle à une opposition marquée (A. Rauch). Dans l'Espagne franquiste, le régime laissa se développer la musique pop, aussi sur le plan commercial, non sans calcul, car il s'agissait de présenter une image "jeune", proche de celle des démocraties occidentales. Cette tolérance suscita plus d'une opposition dans les milieux ultra-conservateurs, non sans raison, car la jeunesse espagnole était entraînée vers d'autres horizons que celui que pouvait leur offrir le Movimiento (P. Otaola Gonzales). Le dernier texte de ce chapitre se penche sur un problème peu connu : la musique électroacoustique a bien existé et même, à certains moments, prospéré en RDA, dès les années 1950 grâce à un studio fondé par la radio nationale, puis après la fermeture de ce studio dans une scène musicale transgressive 
qui, dans les dernières années du régime, se développe rapidement et occupe une place de plus en plus importante (T. Böhme-Mehner).

D. Neumann-Rieser et $\mathrm{S}$. Maurer présentent le projet de recherche Discours de la guerre froide de l'université de Vienne. Il s'agit de dépasser une vision conventionnelle de la littérature autrichienne après 1945 où s'opposeraient conservatisme formel et avantgarde expérimentale. En s'appuyant sur des œuvres négligées, voire redécouvertes, le projet montre que le champ littéraire autrichien fut bien traversé par les tensions propres à l'époque de la guerre froide, conformément à ce qu'affirment les historiens à propos du champ politique. Un premier exemple est fourni par la contribution de G. Stocker à propos d'Insurrection in Poshansk, un roman sur le goulag que Bernd Neumann publia en anglais en 1952 et qui fut traduit la même année en allemand : il n'avait pas fallu attendre L'Archipel du Goulag pour que le système concentrationnaire soviétique soit au centre de la vie intellectuelle et littéraire européenne. L'écrivain Arno Schmidt, qui fut attaqué en justice dans l'Allemagne d'Adenauer pour blasphème et pornographie, passe pour un auteur égocentrique et pessimiste. Son anticonformisme a cependant attiré dès cette époque une communauté de (plutôt jeunes) lecteurs "de gauche", sensibles à sa vision politique progressiste et à son avant-gardisme (J. Doll).

11 Le dernier chapitre, intitulé " Médiations », commence par une étude de l'histoire juive dans les deux États allemands: si la guerre froide a fait obstacle, d'une certaine manière, à une conscience claire de l'ampleur du génocide commis par l'Allemagne hitlérienne, les historiens judéo-allemands Joseph Wulf, en RFA, et Helmut Eschwege, en RDA, ont beaucoup œuvré pour que l'Allemagne rende justice aux victimes de ce crime monstrueux (L. Guillon). E. Lanoë fait le parallèle entre les politiques culturelles de la France et de la RFA au Brésil de 1961 à 1973, en partie à l'époque de la dictature militaire (qui commença en 1964). Il semble bien que mutatis mutandis les politiques culturelles des deux pays aient parfois transmis des contenus "progressistes" conformes à la culture dominante dans la France et l'Allemagne des années 1970, les Alliances françaises manifestant un certain retard par rapport au Goethe-Institut, mais le public brésilien resta limité aux élites. À propos des écrivains de RFA Johannes Tralow, Hans Henny Jahnn, Peter Härtling et Günter Grass, N. Willmann s'intéresse à la médiation des intellectuels entre RFA et RDA. Ces auteurs refusent souvent de renoncer, au nom de l'ancrage à l'Ouest, à l'objectif du maintien de l'unité du pays - au moins sur le plan culturel - et s'attirent le reproche infamant d'être des « compagnons de route " du communisme soviétique et est-allemand.

12 Le progressisme, loin de se réduire à la propagande de l'URSS et de ses satellites, relayée par les compagnons de route du monde occidental, constitue après 1945 un élément central de l'art et de la pensée dans les pays industrialisés des deux blocs. Il ne s'agit pas de nier l'évidence, à savoir la nette ligne de démarcation entre monde « libre » et « démocraties populaires » durant les décennies de la guerre froide, mais de montrer que par delà l'affrontement politique les sociétés se posaient les mêmes questions et étaient parcourues par des tensions semblables, conservatisme et productivisme contre culture pop et critique de la société de consommation, académisme contre avant-gardisme, rigidité morale contre émancipation religieuse et sexuelle, nationalisme et esprit colonial contre antiracisme et ouverture à toutes les cultures du monde. Hormis quelques exceptions, l'Europe et l'Amérique se sont débarrassées de leurs dictatures - « de gauche » et « de droite » - et le progressisme n’a 
pas sombré avec les régimes communistes : l'un des plus forts symboles de sa survie n'est-il pas représenté par la chanson de Woody Guthrie This Land is Your Land, telle qu'elle fut interprétée le 20 janvier 2009 à Washington devant une foule immense par Bruce Springsteen, le très âgé Pete Seeger et une jeune chorale noire, lors de la cérémonie d'investiture de Barack Obama, le premier président noir des États-Unis?

\section{NOTES}

1. G.-H. Soutou, "Conclusions », dans J.-F. Sirinelli et G.-H. Soutou (dir.), Culture et guerre froide, Paris, PUPS, 2008, p. 306.

2. Voir F. Genton (dir. avec la coll. de M. Béghin / U. Bernard / S. Bourgeois / Ch. Eggers / H.L. Ott / G. Vassogne): Heimat: la petite patrie dans les pays de langue allemande. Congrès de l'Association des germanistes de l'Enseignement supérieur, 24-26 mai 2007, Chroniques allemandes, $\mathrm{n}^{\circ} 13$, 2009, 592 p. et A. Delgado Larios et F. Gaudichaud (dir.), Transitions, consolidations, transformations démocratiques : retours critiques et regards croisés Europe/Amérique latine, ILCEA, $\mathrm{n}^{\circ} 13,2010$.

3. Deux exposés seront publiés ailleurs. Nous tenons ici à remercier leurs auteurs de leur participation au colloque. Wolfgang Klein (Osnabrück) a traité de la présence des Lumières dans l'immédiat après-guerre dans une réactualisation allemande et française, dont les acteurs voulaient penser les crimes et les destructions de la guerre tout en cherchant à surmonter les divisions idéologiques et politiques après 1945. Thomas Beutelschmidt (Berlin), partant de l'exemple de la télévision est-allemande, montre comment ce medium, conçu à la fois comme vitrine et porte-parole de l'Allemagne socialiste, dut s'adapter aussi aux formes et aux contenus de la télévision ouest-allemande que presque toute la population de RDA pouvait regarder. Cette convergence n'est d'ailleurs pas une spécificité de la télévision, puisqu'on la constate dans beaucoup d'autres arts, à commencer par l'architecture et d'autres arts visuels.

4. Notre sélection («Prologue », « Marieluise », « Dieter », « Ilona », «Épilogue ») a été montée à partir d'une version fournie par ARTE. Nos remerciements vont à Claire Doutriaux qui avait soustitré et fait diffuser ces films par La Sept sur FR3 en décembre 1990. Une collection complète des films tournés jusqu'en 2007 (18 DVD) est disponible, avec des sous-titres anglais chez l'éditeur Absolut Medien.

5. En France Michel Fresnel a réalisé 12 films d'une heure sur les élèves d'une classe de sixième d'un collège parisien (Que deviendront-ils ? 1984-1993). Le projet anglais (Up Series, Réalisateurs : Paul Almond et depuis 1970 Michael Apted), entamé en 1964, est encore en cours : à la différence $\mathrm{du}$ film allemand, il étudie des individus qui ne se connaissaient pas à l'origine et qui sont pris dans toutes les classes de la société. Les films se composent surtout d'interviews, la vie privée et professionnelle des individus n'étant guère montrée. La dernière série, 56 Up de Michael Apted, a été diffusée les 14, 21 et 28 mai 2012 sur la chaîne privée ITV : ce projet dépasse désormais en durée celui des Enfants de Golzow - qui fut le premier. De tels projets ont existé ou existent encore en Australie, Belgique, Russie, République Tchèque, Afrique du Sud, Suède ainsi qu'au Danemark, aux États-Unis et au Japon. 


\section{AUTEURS}

\section{FRANÇOIS GENTON}

Université Stendhal - Grenoble 3

\section{EDMOND RAILLARD}

Université Stendhal - Grenoble 3 